\title{
Exploring the Incorporation of Values for Sustainable Entrepreneurship Teaching/Learning
}

\author{
Soledad Parra'
}

\begin{abstract}
The objective of the "United Nations Decade of Education for Sustainable Development", during the period 2005 to 2014 is to integrate the principles, values and practices of sustainability in all aspects of education. The aim is to stimulate behavior changes, which will allow the creation of an economic, social and environmentally sustainable future. Sustainable entrepreneurial behavior is relevant for carrying out these changes. This paper tries to find the way to promote a sustainable entrepreneurial vision through the incorporation of new values for teaching/learning of potential entrepreneurs from the moment when the idea is born for creating a for-profit, non-profit or hybrid organization. Generating a change of perspective from the beginning of the entrepreneurship process is sought for fostering the birth of organizations that respect the environment and are responsible when confronting social problems, besides being profitable. All this involves a great challenge to all agents implicated in the process.
\end{abstract}

Keywords: sustainability; entrepreneurship; values; value system; teaching; learning; education. 


\section{Introduction}

The "Decade of Education for Sustainable Development (2005 - 2014)" was proclaimed in 2002 during the United Nations General Assembly. Its objective consists of integrating the principles, values and practices of sustainable development in every facet of education and learning, for promoting the necessary behavioral changes to preserve our planet in the future (UNESCO 2006). The concept of sustainable development was described by the Brundtland Committee in 1987 as what satisfies current people's needs without endangering future generations' ability for satisfying their own needs. Three components are involved: environment, society and economics. Therefore, this paradigm denies that environmental and social losses are inevitable, acceptable consequences of economic development (Mckeown 2002).

Because few issues are characterized by such broad agreement as the role of entrepreneurship for social and economic development (Van de Ven 1986), sustainable entrepreneurial behavior is relevant for carrying out the needed changes of paradigm. Therefore, integrating these concepts of sustainability, development and entrepreneurship through education is very important for encouraging the birth of new sustainable enterprises in the future, since industry has been one of the important contributors to environmental degradation (Cohen and Winn 2007). Extremely complex problems currently come from all three spheres: for example, water and wastes from the environment; equality and peace from society; and, poverty and unemployment from economics (UNESCO 2006).

Therefore, generating a change of perspective is relevant in potential entrepreneurs toward respecting the environment and confronting social problems, besides their desire for a profitable enterprise. This implies a change in the person's value system. It means that from the beginning of the entrepreneurship process, the moment when the idea is born for creating a for-profit, non-profit or hybrid organization (Fowler 2000), or some type of social business (Yunus 2007), entrepreneurs should have a sustainable entrepreneurial vision with the objective of future sustainable entrepreneurial action. This could be possible through the change and incorporation of new values in teaching/learning of potential entrepreneurs which means a great challenge for all agents implicated in the process.

The concept of "sustainable entrepreneurship" is of very recent theoretical formulation, defined in the following three different ways. First it is "the examination of how, by whom, and with what economic, psychological, social, and environmental consequences the opportunities are discovered, created, and exploited to bring future goods and services into existence," (Cohen and Winn 2007, p. 35). Secondly, it is "the process of discovering, evaluating, and exploiting the economic opportunities present in market failures which detract from sustainability, including those that are environmentally relevant" (Dean and McMullen 2007, p. 58). And lastly, it is "the teleological process aimed at the achievement of sustainable development by discovering, evaluating and exploiting opportunities and creating values that produce economic prosperity, social cohesion and environmental protection" (Katsikis and Kyrgidou 2008, p. 2). Therefore, sustainable entrepreneurship would be an area within the larger concept of sustainable development.

If, for consolidating sustainable entrepreneurship, there is a need for promoting new values in potential entrepreneurs to create a new sustainable society, it is necessary to know which are those values, how to teach them, how they are learned, who are involved in the process, how they change, etc. But as this is a recent relationship between subjects there is no specific, synthesized literature about it, so references have been taken from very different areas. Therefore, our approach explores existent literature on relating "education for sustainable development", "sustainable entrepreneurship", "entrepreneurship and ethics", "education in values" and "values" to understand how to incorporate the change of values for teaching/learning sustainable entrepreneurship. And so, if values could be changed through education, mainly at universities or higher education organizations, it would be easier and faster than if entrepreneurs were forced to change through actual life circumstances.

\section{Education for Sustainable Development (ESD)}

ESD is the hope and the best way for achieving sustainable development. It requires people of all professions and social conditions to think critically about things taken for granted and to find creative solutions and alternatives for unsustainable habits and practices (UNESCO 2008). All sectors such as e. g. enterprises, industry, higher education, governments, NGOs, and community organizations should be involved in training for sustainability issues. This means elaborating specialized training programs to ensure that all sectors of the population have the necessary knowledge and competencies for carrying out their work in a sustainable way. This would be possible if vanguard heterogeneous educational strategies were applied for current and future leaders and citizens (UNESCO 2006).

ESD is a process of learning of seven points (7 R's): reducing, reusing, recycling, respecting, repairing, reflecting and refusing. Students should be stimulated to question their excess of consumption through discussions about products, advertisement, etc. Poverty issues should also be incorporated for stimulating solidarity and cooperation (UNESCO 2008). ESD is a fundamental element of a broader discussion about 
the quality of life of all people on earth (UNESCO 2005), which acknowledges than present trends of economic development are not sustainable. Lists of problems are: inefficient use of energy, lack of water, pollution, human rights abuse, overuse of individual means of transport, consumerism, etc. ESD aims to give people abilities and knowledge for learning throughout their lives to help them find new solutions for environmental, economic and social problems (Mckeown 2002).

Some principles of sustainability are gender equality, poverty reduction, environmental rehabilitation, natural resource conservation, social justice and peace. These principles could help define the knowledge, competencies and values that serve as a basis for ESD or that re-orientate current education to include sustainability (UNESCO 2006). Education is a human development facilitator. It does not achieve this purpose by transmitting cognitive information alone. It should provide students with the opportunity to develop a philosophy of life. The end of education is the creation of human beings who have a belief in higher ideals. Such values as truth, freedom, love, respect of human rights, solidarity and democratic conscience, among others, are everlasting and always valid.An education which transmits these values connects the person with what ought to be, and the real with the ideal (Raya 1990)

The relationship between education and sustainable development is complex. On the one hand, more education increases threats to sustainability because people with more education have higher incomes and consume more resources. On the other hand, greener development options increase with higher education, which is necessary for creating greener and sustainable industries. Therefore, the challenge is to raise educational levels without creating an increased demand for resources and consumer goods. This depends on reorienting study plans to deal with production needs and sustainable consumer patterns. Thereby, five components of ESD should be included in an academic program reoriented toward sustainability: knowledge, abilities, perspectives, values and problems. As an integral part of the reorientation process, everything should be deleted that is obsolete or which does not contribute to sustainability. (Mckeown 2002).

Understanding one's own values, the values of the society in which one lives and the values of other people in the world is a fundamental aspect of ESD. In some cultures values are taught openly; in others they are shown as examples, explained, analyzed or discussed. Knowing the values is indispensable for understanding one's own world vision and other people's viewpoints. Since ESD is about learning, it guides and motivates people for participating in a democratic society, to search for more sustainable ways to earn money and to live in a sustainable way (Mckeown 2002). All groups and people must learn to acknowledge their own values and evaluate them with regard to sustainability. And for determining which values to teach and learn, each ESD program should include the values from the local culture relating them to sustainable development (UNESCO 2006).

\section{Definition of Values}

This paper focuses on exploring one of the five components of ESD: values. But first, it makes necessary to explain the distinctions between the words values, morals and ethics. All three have connotations of good and duty and are concerned with human means and ends. Ethics has been seen as an activity which systematizes morals (the ways in which we conduct our lives) into a coherent body of knowledge, while values have a more personal meaning derived from what is of value and gives purpose to an individual or group (Tasker and Packham 1993). Besides, from the philosophical perspective interpretations about value are both subjective and objective. The former asserts that values are the result of individual and collective reactions. The latter affirms that values depend on the object and that the only possible individual action is to capture their worth (Juárez 2004).

Values are relatively stable individual preferences that reflect socialization and seem useful for describing and explaining individual behavior. Literature reveals five common features: They are concepts or beliefs. They deal with desirable endstates or behaviors. They transcend specific situations. They guide the selection or evaluation of behavior and events.And they are ordered by relative importance. Values are cognitive representations of human goals or motivations, those that distinguish one value from another (Bilsky and Schwartz 1994).Values are dynamic and there are several motivational factors that can change them over time. Some of society's components responsible for the process of proliferating an individual's value system include parents and home environment, teachers and other school staff, peers, religious personalities, government, media, and the work environment (Hartsell 2006).

A person's value system depicts a hierarchical organization of learned rules for making decisions and solving conflicts between two or more modes of behavior or end-states of existence. It is a classification order of values through a continuum. This means individuals hold a certain value when they have a lasting belief in a particular mode of behavior or a particular end-state of existence. Both mode and end-state aim at different kinds of values respectively. "Instrumental values" are beliefs about the way we should behave, e. g., responsibly, honestly, etc. Whereas, "terminal values" are beliefs about desirable end-states of existence, e. g., equality, freedom, etc. These two types of value systems 
help choose between alternatives and solve daily conflicts (Rokeach 1968). A person's value system is partly responsible for organizing the profoundly different perceptions of the psychological, physical and social world, between the unhappy person and the mentally healthy person. For unhappy people the world is a dangerous place, a jungle, an enemy territory inhabited by those whom they dominate and those who could dominate them. Meanwhile, the value system of healthy people is related to superior needs (Maslow 1991).

A value is a criterion that tells us how to act, what to desire, which attitudes to maintain. We use it to justify our behavior, to judge morally and to compare ourselves with others. It allows us to evaluate whether others' values, attitudes and actions are a worthy influence or not. So, in any given situation individuals cannot be congruent with all their values, because the situation can activate one value in conflict with another (Rokeach 1968). Many psychologists conclude that it is individuals' value system that determines who, what and where they are and how they relate to self, to their family, other people, their job, and the whole world around them (Mankoff 1974).A value involves aspects of psychological life beyond the strictly cognitive. This means values are different from other factual beliefs due to their metaphysical objects. The object for which a value aims is goodness. Therefore compassion, integrity, wealth, honesty, protection of wildlife, etc. are goods to be pursued (Carr 1991).

Finally, values can be quantified, compared and modified. This means that a lasting change in attitudes could sometimes be quickly achieved when the discrepancies in an individual's value system can be shown to him (Mankoff 1974). Values could change with some difficultly. For example, alterations in one's main life circumstances may force a change, although the transition and adjustment of values might be slow and painful (Plant 1997). Values are measured by means of questionnaires. The most common general value inventory has been provided by Rokeach (1973), while others have been derived from this one. The most well-known are Kahle's list of values (LOV, 1983) and the Schwartz-Bilsky inventory (1987, 1990) (Jolibert and Baumgartner 1997).

\section{Development of Values}

Values development have been differentiated as "upward", described as the trend toward achievement vs. "downward" or the route of heritage and tradition. The former is the empirical method beginning with experience, understanding, rationality and value (EURV), while the latter progresses in reverse order: value, rationality, understanding and experience (VRUE). The latter means that one accepts a value because it appears to come from reliable and valued forces like parents or teachers. But people's reliance on the route of achievement throughout life is enhanced while the route of heritage becomes diminished (Eidle 1993).
An important issue in changing values is where those values came from, perhaps from life's evaluated human experience. If the student's experience is a curriculum without humanity, it only contributes to inhumanity. It is necessary to impart an understanding of the interdependence of mankind and of the fragility of human societies (Tomlinson 1997). People are not born ethical, but they obtain moral awareness during their personal development. Ethical behavior is an exercise in freedom. It means deciding voluntarily and freely to do the right thing, following reasonable universal rules. If people act through obligation it would not be ethical (Camps 2000).

Three major theories of value formation differ with regard to how values originate and become an established guideline in the lives of those who possess them. First, the psychoanalytic theory of value formation holds that our superego or unconscious conscience, allows us to suppress or neutralize urges that would violate moral rules. Secondly, the social learning theory simply states that values are learned through the direct positive and negative reinforcement of behavior; the formation of a value system depends on the control exerted by society (punishment and reward). Finally, the third model of moral development recognizes six stages. Stages one through four are characterized by an adherence to forms of conduct that have positive consequences, regardless of their inherent value or meaning. At stage five, individuals begin to appreciate the social definitions of right and wrong and to adopt the standards of the society as their own. And the final stage, one of full moral autonomy, sees the individual moving away from rules of obligation toward what is ethically just. At this stage of self-actualized moral reasoning, students begin to consider the consequences of actions to discover the inherent value of ideas, and with the right guidance, to develop a lasting respect and compassion for life (Hartsell 2006).

Finally, there is one ethical environment. All our ideas about how to live are part of it and it influences the moral development of any given individual. Some ethical ideas have global value such as the notion of human rights. The ethical environment is also marked by diversity and should include understandings which will set the context for a person's emotional responses and motivations to act. It is internalized within us, but at the same time the ideas, expectations, demands and reactions of real people around us are also a part of every person's ethical environment. Besides, the environment can be healthy or unhealthy (physically or psychologically good or bad). It seems plausible that unhealthy ethical environments are unlikely to be sustainable over the long run. The healthiness and the sustainability of an environment are relevant when considering changes that may happen to it (Haydon 2004). 


\section{Change of Values}

Individuals have a need to maintain coherence between all the elements of their value-attitude system, but several of these are daily taken to a dissonant relationship with others. That is, the individual might undergo a contradiction between two beliefs, or between an instrumental value and a terminal one, or between a value and an attitude. An attitude is defined as a lasting organization of several beliefs focused on an object or situation that predisposes an answer in a preferential way, while a value transcends objects and situations. The valueattitude system creates an internal, psychologically coherent, hierarchical mental organization. This means that any change in one part of the system will affect the rest and should lead to a change in behavior. It is suggested that the most lasting and transcendental changes inside the value-attitude system would be made when one or more terminal values are taken inside a dissonant relationship with other elements of the system, i. e., with another terminal value, with an instrumental value or with an attitude. These dissonant relationships should increase motivational forces that lead individuals to change their values and attitudes to make them psychologically more coherent (Rokeach 1968).

Research has shown that changes in values, attitudes and behavior are possible as a result of objective feedback of information about one's own values and attitudes, and those of others. Feedback makes people conscious of contradictions in their own value-attitude system, resulting in longterm cognitive and behavioral changes. Besides, there is evidence that the psychological mechanism that generates a process of change is the arousal of an affective state of self-dissatisfaction, whose source is specific and identifiable. For reducing individuals' self-dissatisfaction, it is necessary to reorganize their values, attitudes and behavior to make them mutually compatible and with self-concepts. If people were encouraged to look more closely at their own values and attitudes, at the various inconsistencies observed within their own value-attitude system, and at the inconsistencies observed within the value-attitude systems of others, this would lead to better informed people who would be influenced to change their values and attitudes in the direction of becoming more internally coherent and more mature, selfaware and enlightened. If individuals claim holding a value, they will desire to influence others to have it too. Lastly, it is assumed that thousands of attitudes serve and relate to only a few dozen instrumental values, which simultaneously serve and relate to approximately a dozen terminal values (Rokeach 1968).

\section{University Values vs. Industry Values}

\section{University Values:}

There is a growing consciousness of the need for a fundamental change in values. Ethics is essential for facing the problems of our society today (moral and cultural in nature). Profound differences about ends and means can be found between the business and academic worlds. A university serves society by appreciating the discrepancies between intellectual standards and market practices. On the one hand, the purpose of higher education should be to provide an inquiry into the meaning of the good of individuals and the world. Its purpose is for people to be able to think autonomously, critically and in dialogue committed to freedom and democracy that can act as a source of independent criticism in its areas of competence; an education that frees the mind. Only the university can approach these activities on the moral level for promoting open inquiry and service to humanity (Tasker and Packham 1993).

Besides, knowledge has a moral character and a pedagogical mission. It is a psychic phenomenon. It not only defines objects, it is also self-definition. Students should learn to think, reason, compare, discriminate and analyze, to refine their taste, forming their judgment and sharpening their mental vision. They should embrace certain values which would give stability to their being and represent the ideals for living. Human lives have no direction without values, which motivate human will. Free acceptance of values determines the human personality (Raya 1990).

Deduced from the above, the values transmitted by professors at the university can increase students' respect for truth, for their own worth and the rights of other people, their love of wisdom or service to humanity, their awareness of the ignorance and smallness in this vast universe, and their inquiring mind in order to discover higher perspectives in life (Raya 1990). Maslow analyzes the behavior of self-actualized professors, whose conduct is of collaboration and not a collision of wills, authority and dignity. They substitute artificial dignity for a natural modesty that is not easily threatened. They renounce trying to be omniscient and omnipotent, omit threatening authoritarianism, reject assuming the stereotype of professor and insist on remaining naturally human. This creates a classroom atmosphere where disappears the suspicion, caution, defensiveness, hostility and anxiety (Maslow 1991).

\section{Industry Values:}

On the other hand the conduct of industry cannot be amoral nor can it operate in a value-free way, because its decisions involve moral choices and imply taking a value posi-

ISSN: 07 I8-2724. (http://www.jotmi.org)

Journal of Technology Management \& Innovation (c) Universidad Alberto Hurtado, Facultad de Economía y Negocios. 
tion whether recognized or not. Such decisions determine, among other things, the nature of the product, management, personnel, customers' relationship and attitudes toward the environment. Besides, industry plays a role in forming and expressing the moral values and in shaping the value systems of individuals and of society in general. This influence is unacknowledged because industry was unproblematic for many years. Consequently its values were widely accepted. For decades people have not questioned the need of industry to produce more goods, exploit more raw materials or penetrate more markets. But these values are not immutable or inevitable (Tasker and Packham 1993).

Multinational companies, however, absorb part of the social function that shows models and ideals to motivate young people, through advertising messages. The values transmitted from the multinational viewpoint try to homogenize people's consciences to becoming incapable of facing daily troubles with reasoning, originality, a critical spirit, coherent attitudes, etc. They intend to offer standard solutions based more on having than on being (Pereira and Pino 2005). Clearly the poorest and the most affluent young people are imprisoned by our culture's obsession with material things. From an early age they get the message that, in order to feel good about them or to be loved, they need to look a certain way or own the latest designer jeans (Lantieri and Nambiar 2004). Consumerism is a twentieth century phenomenon and represents the values of the capitalism: the pursuit of profit and the maximization of economic growth. In the consumerist culture the accumulation of worldly goods is seen as essential to existence, as a good in itself. Also in recent years, enterprises and entrepreneurship have become sullied by the business malpractice and environmental abuse with which they are associated (Tasker and Packham 1993).

When an organization decides to apply a value-based strategy for change, it opens the door for its people to move toward Maslow's ideal of self-actualization. The question is whether it is possible for a business consisting of a majority of self-actualized people to survive in the present business environment, where predominant values are materialism, competition, individualism and selfishness. But businesses cannot continue ignoring human needs, because their profit-directed value is in conflict with any basic and universal humanistic scheme of values. The business environment will evolve a value system that encompasses a degree of humanism, and the result should be an organization that exhibits a concern for human needs, the environment and the entire world (Mankoff 1974).

Debates about the future of capitalism under the pressure of environmental and social problems are increasing nowadays. New literature on business and management contributes to the trend in ethical awareness. On the one hand, focus is on economic growth as the means to the end of acting responsibly to shareholders, and on the other hand, on limits to growth as the means to the end of achieving ecological and human rights in the world. While the role of industry still continues to be maximization of growth and profits, there are shifts in people's consciousness about environmental and social issues which might indicate changing values. Traditional Fordist values of hierarchy, power and control are giving way to post Fordist values of autonomy, responsibility and collaboration. A value change requires abandonment of the principle of ever increasing production and consumption and adoption of limits to growth to a minimum or for sustainable development (Tasker and Packham 1993).

\section{Teaching/Learning of Values}

How can ethics be taught? It is easier explaining how it should not be taught: as a subject. Ethics is learned by example and practice. It is learned when conflicts are faced in a collective way. While our day is one of individualism based on aggressive competence and the demand of rights but not of duties, educating in ethics means teaching responsibility, feeling co-responsible for the public, for all people. It is to educate for attending to others. Therefore, it is educating crosscurrent without expecting anything more than the satisfaction of acting as one should (Camps 2000). What pedagogical approach might best serve to implement values? Cognitive researchers give guidance for this implementation by subscribing to a constructivist view of education that emphasizes the active role of the learner in the learning process. The central idea is that students construct their own understanding as they engage in meaningful and relevant learning experiences. It means they are not passive but that they actively construct their own meanings (Lantieri and Nambiar 2004).

Learning values is rarely studied in literature although teaching values must engage the learner's process. Learning values should have: a) a process condition: optimal conditions for the integration of values into students' lives would include students' voluntary commitment; b) a conceptual condition: values learning should lead to personally transformed relationships between students and the topics considered worthwhile; and c) a contextual condition: since learning values is the core of formal education, there has to be some consistency between what is learned and the wider sociopolitical scene. Because teaching values is crucial to education, it should become a consciously internalized guide for behavior (Silcock and Duncan 200I).

Real learning and understanding are holistic and emerge from active experiences that make sense to learners. Therefore, developmental changes that occur over time in young people play an important role in the learning process. Values can be learned in a profound and genuine way that becomes 
part of each learner's repertoire for acting in the world. The concept of values grows over time. It is formed gradually with new learning built on earlier learning through a long and slow developmental process. This growth process is a continuous differentiation and integration that separate concepts and feelings and order them as a whole - a process which is time-consuming, troubled, and laborious (Lantieri and Nambiar 2004).

An exploration of values allows the increase of student awareness of their own and others' ethics. An atmosphere for analyzing or reinforcing the value system helps students feel confident enough to risk expressing their differing views. Teachers can encourage students to listen to one another even if they do not agree, guiding a discussion where issues are challenged but individuals are not attacked, and dealing with inappropriate responses in a positive way. Teachers are facilitators of the process, teaching value clarification skills, but not the values themselves. Therefore it is necessary to resist the urge to make judgments about which values are better or worse. Teachers should help participants develop ideas, acting as mediators of disputes that arise from differing viewpoints, and as assessors of their students' progress. Students should acquire a perception of the teacher as a caring individual who is dedicated to promoting self-growth. If the teacher fails to understand the reasoning behind a student's point of view, then each one might question the other one's ability to listen, resulting in a breakdown (Hartsell 2006).

A knowledge transmitter professor must become an educator professor who profoundly reviews teaching methods by following these methodological principles: a) learning is personal, b) thinking abilities can develop, c) learning can be stimulated by the professor and d) the most important learning corresponds to a value. The professor should implicitly introduce a group of values useful for the society. Students would learn not only knowledge, but would be critical of stating value judgments based on values (Juárez 2004). The values dimension serves as a corrective to those technical approaches to teaching which serve to reduce teaching performance to mechanistic and instrumentalist criteria, with the view that practice is value-free. There is a component of values in all learning, because knowing cannot be neutral and any learning entails an encounter with values. A good value education requires vision, leadership, intentionality, creativity, communication and cooperation (Lovat and Clement 2008).

The education mission transmits knowledge integrated in a culture and an ethical dimension. This makes for educating in ethical values, those that form the character and allow the promotion of a more civilized world. Values need to become conscious (Camps 2000). One way of defining our most basic values is to see them as intrinsic to all our actions and decisions. For a value to become with personal force, it must relate somehow to our characteristic behavior. It should be more than an ideal to which we aspire (Silcock and Duncan 200I).

\section{Methods for Teaching/Learning of Values}

The methods for providing a value-oriented education are many and varied. Some activities are recommended for sensitizing students such as their dynamism for the desire to know and for deliberating on values and the relevant role of values in their living. The courses of achievement or of heritage-tradition could include exercises associated with these routes and others for attaining awareness that the values held in each course are different. A values-education context/climate could assist reflection on integral relationships such as self-esteem, the formation of values and the valueguided behavior. Students should identify exactly "what my values are" and identify value issues in various situations. They should also critique their values: consistency, reciprocity, coherence, comprehensiveness, adequacy, duration, authenticity and openness (Eidle, 1993).

Values are relevant in any decision situation and alternatives are important only because they allow those values to be achieved.Value-focused thinking can improve decision making because it leads to the creation of better alternatives and to the identification of better situations for decisions, such as opportunity decisions rather than problem decisions. The process of identifying and understanding objectives is crucial for making the values explicit that are related to a given decision situation. It begins by asking: what would you like to achieve in this situation? Then it generates thoughts about consequences, impacts, equity, fairness, concerns, etc., that make implicit objectives explicit. Values are identified by examining the answers about the meaning of objectives (Keeney 1993).

To teach values across the university curriculum there are alternative approaches to incorporating critical thinking about values. The first could be that all first-year students take an introduction to ethics or a moral problems course in the philosophy department. The second approach could be creating a new course such as "Critical Thinking about Values" that would be taught by interested faculty regardless of their departmental affiliation. The third could be the approach of teaching values across the disciplines which requires faculty to incorporate discussions of values into the introductory courses they normally teach. This latter could be the most suitable for helping students see that even the most empirical disciplines make assumptions and give rise to questions about value (Katzner and Nieman 2006). 
One of the most innovative methods of training for integrating topics of sustainability is the competences model where all disciplines and all professors can contribute to education for sustainability. To apply this model it is necessary first to ensure that professors and managers understand the concept of sustainability and know its principles. Then they could examine study plans and educational activities to include examples, knowledge, issues, perspectives, capacities or values related to sustainability. The synergic competences of the educational disciplines combined could transmit them openly to students in various programs. This is a multidisciplinary task that includes pedagogical techniques and strategies combined for transmitting creativity, critical thinking and the desire for learning throughout life, which are mental habits for favoring sustainable societies (UNESCO 2005).

The study of the causes of a problem, the precaution against possible future problems based on various hypotheses, the comprehension that a lot of world problems are related, and the capacity for examining a problem from viewpoints other than one's own are fundamental. Such analysis guides a major understanding for creating the climate of cooperation that supports sustainability. Examples of practicing programmatic reforms for sustainability include the following: asking students to serve as volunteers in a non-profit local organization; offering an intensive ESD seminar to professors; student acquisition of experience in environmental education; placing students in a social-economical or cultural context different than their own; and providing the opportunity to contemplate a building using sustainable practices within regulations. When students can observe recycling or the use of products that respect the environment, they will reflect on practices that contribute to major sustainability (UNESCO 2005).

\section{Conclusions}

Literature about diverse subjects related to education, sustainability and values has been explored in the search for how to incorporate new values for teaching/learning a future sustainable entrepreneurship. This review permits a conclusion with some reflections that are expected to lead to a better way for achieving this. Our purpose is to promote the development of this new kind of "sustainable entrepreneur" according the new paradigm of sustainability. This new concept of sustainable entrepreneur embraces the other three kinds of entrepreneur: the opportunity entrepreneur, the needed entrepreneur (Coduras et al. 2003) and the social entrepreneur (Dees 1998).

Entrepreneurs are leaders. Therefore they are a relevant focus for applying ESD.They could use their creativity to search for solutions to the social and environmental problems related to their future organization. From the beginning of the entrepreneurship process they could incorporate the 7Rs (reducing, reusing, recycling, respecting, repairing, reflecting, and refusing) in their decision-making. To do so, traditional teaching/learning of entrepreneurship must be reoriented toward sustainability. Some of its values must be incorporated such as natural resource conservation, cooperation, etc. The objective should be to incorporate sustainable values in each process, activity and relationship of the future organization (value chain, value system of suppliers, channels and consumers, etc.) - to incorporate them in the business idea and business plan. Some obsolete or unsustainable values must also be omitted, such as profit maximization without considering the social and environmental context.

If entrepreneurs understand their own and other people's values, they could have a better understanding of actual market changes toward sustainability. Self-knowledge is needed for obtaining a healthy vision of society.Teaching/learning sustainability could show and discover ethical conflicts between some elements of their own value system (e.g. competence vs. cooperation) for a quicker change of behavior toward sustainability. The information feedback that allows awareness of the contradictions, inconsistencies or dissonant relationships among some elements in the entrepreneur's value system could produce a search for psychological coherence to reduce that self-dissatisfaction through a lasting change of values, attitudes or behavior for sustainability.

The future sustainable entrepreneur must learn to think, reason, compare, discriminate and analyze for attaining a sustainable vision, besides having a critical spirit and coherent attitudes. This would allow abandoning ever increasing production and consumption to adopt limits to growth to reach a sustainable boundary. These new entrepreneurs should be responsible and feel co-responsible for the public. They should have an active role in learning from experiences that make sense to them. If the formation of unsustainable values comes from heritage, teaching/learning for sustainability could change the process toward the course of achievement (EURV). If entrepreneurs have learned unsustainable values through the positive reinforcement of behavior (e. g. money alone), then the increasing healthy, sustainable ethical environment due to the new society's awareness could influence them through social punishment for unsustainable behavior. With the help of teaching/learning for sustainability entrepreneurs could be expected to achieve the sixth stage of the moral development model of value formation. Besides, they would need to evaluate the objectives for making the values explicit that are related to a given decision situation and for understanding the future consequences and impact of their behavior.

Teaching/learning sustainability related to the entrepreneur is a multidisciplinary task. It would help if the approach of 
teaching values across disciplines would be applied at higher education institutions. Also, sustainable values could be applied in any specific entrepreneurship course, on any person interested in the entrepreneurship process with the idea of creating a new organization in the future. Then entrepreneurs would need to change their goals for attaining ever sustainable new configurations, behavior and results. Finally, it is important to highlight that Payne and Joyner (2006) question the areas where entrepreneurs should make ethical decisions during the creation and development process of a new organization. They have identified four categories of ethical values held by entrepreneurs: a) individual entrepreneurial values (honesty or integrity), b) employee/cultural values (organizational culture and employee well-being), c) customer/quality values (products/services quality and consumer satisfaction) and d) external accountability values (issues relating to community, natural environment, political and legal responsibility, and accountability to the stockholders). If entrepreneurs feel that ethical behavior is at the core of long term business success, ethics will be more important for them (Clarke and Aram 1997).

\section{References}

BILSKY, W. and Schwartz, S. (1994) Values and personality. European Journal of Personality, 8, 163-|8I.

CAMPS, V. (2000) Los valores de la educación. Eduxunta. http://www.eduxunta.es/valora/files/camps.pdf

[Accessed March 22, 20I0].

CARR, D. (199I) Education and Values. British Journal of Educational Studies, 39 (3), 244-259.

CLARKE, R. and Aram, J. ( 1997) Universal Values, Behavioral Ethics and Entrepreneurship. Journal of Business Ethics, 16, $561-572$.

CODURAS, A., López-García, P., Justo, R. and De La Vega, I. (2003) GEM: Global Entrepreneurship Monitor: Informe Ejecutivo 2003, España. Cátedra Najeti, Instituto de Empresa, I-I04.

COHEN, B. and Winn, M. (2007) Market imperfections, opportunity and sustainable entrepreneurship. Journal of Business Venturing, 22, 29-49.

DEAN,T. and McMullen, J. (2007) Toward a theory of sustainable entrepreneurship: Reducing environmental degradation through entrepreneurial action. Journal of Business Venturing, 22, 50-76.

DEES, G. (1998) Enterprising Nonprofits. Harvard Business Review, Jan-Feb, 55-67.

EIDLE, W. (1993) Values, Education and Self-Esteem. Education, II3 (4), 66I-67I.

FOWLER, A. (2000) NGDOs as a moment in history: beyond aid to social entrepreneurship or civic innovation? Third World Quarterly, 2I, (4), 637-654.

HARTSELL, B. (2006) Teaching Toward Compassion: EnvironmentalValues Education for Secondary Students. The Journal of Secondary Gifted Education, 17 (4), 265-27I.

HAYDON, G. (2004) Values education: sustaining the ethical environment. Journal of Moral Education, 33 (2), I I5-129.

JOLIBERT,A. and Baumgartner, G. (1997) Values, Motivations and Personal Goals: Revisited. Psychology \& Marketing, 14 (7), 675-688.

JUÁREZ, J. (2004) La Formación en Valores como Principio Rector de la Calidad Educativa en las Universidades. Logoi Univ. Católica Andrés Bello, 7, I5I-I79.

ISSN: 07 I 8-2724. (http://www.jotmi.org) 
KATSIKIS, I. and Kyrgidou, L. (2008) The Concept of Sustainable Entrepreneurship: a Conceptual Framework and Empirical Analysis. Academy of Management Proceedings, I-6.

KATZNER, L. and Nieman, D. (2006) Making Values Education Everyone's Business. About Campus, Nov-Dec, 16-23.

KEENEY, R. (1993) Creativity in MS / OR: Value-Focused Thinking - Creativity Directed toward Decision Making. Interfaces, 23 (3), 62-67.

LANTIERI, L. and Nambiar, M. (2004) Sustaining the Soul that Serves: Healing from Within. Reclaiming Children and Youth, $13(2), 120-124$.

LOVAT,T.y Clement, N. (2008a) Quality teaching and values education: coalescing for effective learning. Journal of Moral Education, 37 (I), I- 16.

MANKOFF, A. (1974) Values - Not Attitudes - Are the Real Key to Motivation. Management Review, December, 23-29.

MASLOW, A. (I99I) Motivación y Personalidad. Ediciones Díaz de Santos, Madrid.

MCKEOWN, R. (2002) Manual de Educación para el Desarrollo Sostenible. Education for Sustainable Development Toolkit. http://www.edstoolkit.org [Accessed March 8, 20I0].

PAYNE, D. y Joyner, B. (2006) Successful U.S. Entrepreneurs: Identifying Ethical Decision-making and Social Responsibility Behaviors. Journal of Business Ethics, 65, 203-2I7.

PEREIRA, M. y Pino, M. (2005) Globalización y Educación en Valores. Aportaciones Educativas desde el Fenómeno Social de la Muñeca Barbie. Revista Galega do Ensino, 13 (47), |42I-|44|.

PLANT, P. (1997) Careerist, Wage-Earner or Entrepreneur: Work Values and Counseling. Journal of Employment Counseling, 34, 165-170.

RAYA, A. (1990) Can knowledge be promoted and values ignored? Implications for nursing education. Journal of Advanced Nursing, I5, 504-509.

ROKEACH, M. (1968) The Role of Values in Public Opinion Research. 547-559.

SILCOCK, P. and Duncan, D. (200I) Values Acquisition and Values Education: Some Proposals. British Journal of Educational Studies, 49 (3), 242-259.
TASKER, M. and Packham, D. (1993) Industry and higher education: A question of values. Studies in Higher Education, 18 (2).

TOMLINSON, J. (1997) Values: The Curriculum of Moral Education. Children \& Society, I I, 242-25I.

UNESCO (2005) Directrices y recomendaciones encaminadas a reorientar la formación de docentes para abordar el tema de la sostenibilidad. La educación para el desarrollo sostenible en la práctica. Documento técnico $\mathrm{N}^{\circ} 2-2005$.

UNESCO. http://www.unesco.org [Accessed March 8, 20I0].

UNESCO (2006) Decenio de las Naciones Unidas de la Educación para el Desarrollo Sostenible (2005-20/4): Plan de aplicación internacional. UNESCO. http://www.unesco.org [Accessed March 8, 20I0].

UNESCO (2008) La Contribución de la Educación Inicial para una sociedad sustentable. UNESCO. http://www.unesco.org [Accessed March 8, 20I0].

VAN DE VEN, A. (1986), Central Problems in the Management of Innovation. Management Science, 32 (5), 590-607.

YUNUS, M. (2007) Creating a World without Poverty, Social Business and the Future of Capitalism. Public Affairs, New York. 